\title{
Unilateral Direct Carotid Cavernous Fistula Causing Bilateral Ocular Manifestation
}

\author{
Zeferino Demartini Jr. Fernando Liebert Luana Antunes Maranha Gatto \\ Thiago Simiano Jung Carlos Rocha Jr. Alex Marques Borges Santos \\ Gelson Luis Koppe \\ Cajuru Hospital, PUCPR, Curitiba, Brazil
}

\section{Key Words}

Exophthalmos · Papilledema - Carotid artery injury · Carotid cavernous sinus fistula · Endovascular procedure · Therapeutic embolization

\begin{abstract}
Unilateral carotid cavernous fistula presents with ipsilateral ocular findings. Bilateral presentation is only seen in bilateral fistulas, usually associated with indirect (dural) carotid cavernous fistulas. Direct carotid cavernous fistulas are an abnormal communication between the internal carotid artery and the cavernous sinus. They typically begin with a traumatic disruption in the artery wall into the cavernous sinus, presenting with a classic triad of unilateral pulsatile exophthalmos, cranial bruit and episcleral venous engorgement. We report the case of a 38-year-old male with traumatic right carotid cavernous sinus fistula and bilateral ocular presentation successfully treated by interventional neuroradiology.

(C) 2015 The Author(s)

Published by S. Karger AG, Basel
\end{abstract}

\section{Introduction}

Carotid cavernous fistulas (CCF) are uncommon disorders characterized by abnormal communications between the internal carotid artery (ICA) and the cavernous sinus (CS) [1, 2]. Barrow et al. [1] divided CCF in four categories, with direct communications between ICA-CS characterizing type A. Types B, C and D are indirect dural shunts, having low blood flow [2]. Direct and indirect fistulas have different pathogenesis, with the last arising from meningeal arteries of the external and/or ICA [2]. Direct connections have a high flow 
Demartini Jr. et al.: Unilateral Direct Carotid Cavernous Fistula Causing Bilateral Ocular Manifestation

through the ICA wall and are posttraumatic in $75 \%$ of cases $[1,3]$. Other etiologies include cavernous ICA aneurysm rupture, arterial dissection, connective tissue disorders, iatrogenic causes and fibromuscular dysplasia [2, 4-6]. The mixing of venous and arterial blood leads to a venous hypertension transmitted to the orbital content. The classic clinical triad is pulsatile exophthalmos, cranial bruit and episcleral venous engorgement [2]. Fremitus, chemosis, ocular nerve palsy, increased intraocular pressure (IOP) and retinal hemorrhages may also occur, with all manifestations usually being ipsilateral to the fistula $[1,2,4]$. We report a case of a patient with traumatic unilateral direct fistula and bilateral ocular presentation.

\section{Case Report}

Ten months after a head trauma due to a road accident, a 38-year-old man presented frontal headache, low visual acuity (VA), increased volume and progressive conjunctival hyperemia in both eyes, with recent worsening. Ophthalmologic examination showed VA of count fingers in both eyes. Ectoscopy showed no pulsatile proptosis, ophthalmoparesis and bilateral chemosis were worse in the left eye (fig. 1a). Biomicroscopy showed epibulbar injection and exposure keratitis in both eyes. Tonometry was $27 \mathrm{~mm} \mathrm{Hg}$ in the right eye and $28 \mathrm{~mm} \mathrm{Hg}$ in the left eye. Extensive bleeding, major venous ectasia and bilateral papilledema were seeing in the fundoscopy and fluorescein angiography (FA) (fig. 2a-d). CT scan with contrast showed proptosis, diffuse thickening of the extra-ocular muscles and bilateral dilatation of the ophthalmic veins. Ophthalmic treatment with hypotensive eye drops and acetazolamide orally decreased levels of IOP to $18-20 \mathrm{~mm} \mathrm{Hg}$. The exposure keratitis had significant improvement with ophthalmic ointment, lubricants and eye bandage. Cerebral digital subtraction angiography (DSA) showed right high-flow CCF, Barrow Type A, venous hypertension contralateral filling of CS (fig. 3a), and bilateral ectasia of the superior ophthalmic veins (fig. 3b). Through the same right femoral artery access, the catheter was changed and the fistula was catheterized with a microcatheter. Endovascular treatment was then performed positioning detachable balloons and coils into the right CS, interrupting the arteriovenous communication. Immediate postoperative control DSA confirmed total occlusion of the fistula with patency of the ICA (fig. 3c). Postoperatively, the patient had progressive decreasing of chemosis and proptosis, with discharged $48 \mathrm{~h}$ after presenting a right VA of $20 / 80$ and a left VA of 20/100 and IOP of $12 / 12 \mathrm{~mm} \mathrm{Hg}$, without hypotensive eye drops or acetazolamide. Ten day after the procedure, FA revealed mild right papilledema and rare bilateral microhemorrhages. After 3 weeks, the patient had a normal external examination (fig. 1b). At follow-up, 90 days after the embolization VA was 20/20, with normal IOP and fundoscopy.

\section{Discussion}

The CS is a lateral sellar compartment, converging several sources of venous blood and crossed by the ICA [2]. Aquini et al. [7] described four interconnections between the CS. The widest connection in most of the cases is with the basilar plexus, present in $100 \%$ of the cases [7]. Other communications vary in size; the anterior and posterior inter-CS are always present, whereas inferior inter-CS sinus is present in $97 \%$ of the cases $[2,7]$.

Direct fistula typically begins by an ICA wall bursting into the CS, usually producing lesions less prone to natural closure than indirect fistulas due to high flow [1]. The ipsilateral eye is the most affected organ, ranging from mild episcleral expansion to exuberant clinical 
Demartini Jr. et al.: Unilateral Direct Carotid Cavernous Fistula Causing Bilateral Ocular Manifestation

picture, with secondary glaucoma, severe proptosis and retinal hemorrhages [1] as in this case. Bilateral presentation is usually associated with bilateral indirect CCF. Although bilateral traumatic CCF may occur in 1-2\%, unilateral CCF with ipsilateral symptomatology is far more common [2]. Unilateral fistulas with bilateral symptoms are rare because despite communications between the CS, there is a major decompressive route through the ophthalmic veins [2]. Contralateral venous ectasia requires wider communication between CS, possibly associated with a specific defect in the artery wall directing the inflow to the intercavernous sinus.

Diagnostic imaging of CCF include CT, MR, CTAngio and MRAngio, which can show asymmetric CS widening, orbital vein and extra-ocular muscles enlargement [2]. Whereas a completely normal exam does not exclude CCF, high clinical suspicion should follow DSA, the gold standard for the diagnosis and classification [2, 8]. DSA besides identifies location, size of the fistula and venous reflux, likewise allowing immediate treatment [4].

Ideally, the treatment should be performed when the lesion is diagnosed, and prompt treatment of high flow fistulas is recommended $[2,4,9]$. Even if most of the CCF is not life threatening, venous reflux causing intracranial hemorrhage or massive epistaxis can be fatal $[4,8,10]$. Angiographic image of dilated CS with extension into the subarachnoid space and pseudoaneurysm was associated with fatal hemorrhage by Halbach et al. [4]. Increased intracranial pressure, proptosis with untreatable corneal exposure, visual deterioration, hemorrhage and transient ischemic attacks require emergent or aggressive intervention $[1,4$, 11]. Treatment indications may either include diplopia, intolerable headache or bruit, secondary glaucoma and anterior segment ischemia [1].

The management of ocular symptoms may help, but the definitive treatment is focused on reducing venous pressure. Earlier, the surgical technique was based on carotid ligation, depending on the existence of collateral blood flow to maintain cerebral perfusion, later evolving to endovascular deployment of the detachable balloon [12]. Several approaches have been described: arterial, transfemoral transvenous, puncture of superior orbital vein and combined $[5,13]$. The endovascular approach preserving the ICA is currently the treatment of choice for these lesions and can be performed positioning detachable balloons into the CS through the fistula $[5,13]$. In addition, coils deployment is a frequently used technique and can be associated with either stents or flow diverters to avoid coil herniation [3, 6]. Fistula occlusion with covered stents is a useful method [14]. In this case, balloon deployment reduced the flow but failed to totally occlude the fistula, requiring the use of detachable coils.

The clinical improvement mainly depends on the evolution time until fistula resolution, with timely intervention avoiding irreversible neuropathies [11]. Immediate treatment as in this case allows better results, with early hospital discharge and complete patient recovery.

\section{Statement of Ethics}

The study was approved by the Research Ethics Committee of the Hospital Universitario Cajuru.

\section{Disclosure Statement}

The authors report no conflicts of interest concerning the materials or methods used in this study or the findings specified in this paper. 
Demartini Jr. et al:: Unilateral Direct Carotid Cavernous Fistula Causing Bilateral Ocular Manifestation

\section{References}

1 Barrow D, Spector R, Braun I, Landman J, Tindall S, Tindall G: Classification and treatment of spontaneous carotid-cavernous sinus fistulae. J Neurosurg 1985;62:248-256.

-2 Tytle TL, Punukollu PK: Carotid cavernous fistula. Semin Cerebrovasc Dis Stroke 2001;1:83-111.

-3 Morón FE, Klucznik RP, Mawad ME, Strother CM: Endovascular treatment of high-flow carotid cavernous fistulas by stent-assisted coil placement. AJNR Am J Neuroradiol 2005;26:1399-1404.

-4 Halbach VV, Hieshima GB, Higashida RT, Reicher M: Carotid cavernous fistulae: indications for urgent treatment. AJNR Am J Neuroradiol 1987;8:627-633.

5 Kobayashi N, Miyachi S, Negoro M, Suzuki O, Hattori K, Kojima T, et al: Endovascular treatment strategy for direct carotid-cavernous fistulas resulting from rupture of intracavernous carotid aneurysms. AJNR Am J Neuroradiol 2003;24:1789-1796.

6 Iancu D, Lum C, Ahmed ME, Glikstein R, Dos Santos MP, Lesiuk H, et al: Flow diversion in the treatment of carotid injury and carotid-cavernous fistula after transsphenoidal surgery. Interv Neuroradiol 2015;21:346-350.

7 Aquini MG, Marrone ACF, Schneider FL: Intercavernous venous communications in the human skull base. Skull Base 1994;4:145-150.

-8 Pouw AE, Rabin RL, Karanjia R, Bababeygy SR, Amar AP, Sadun AA: Angioarchitectural evolution of clival dural arteriovenous fistulas in two patients. Case Rep Ophtalmol 2015;6:93-100.

$>9$ Iida K, Kurisu K, Arita K, Ohba S, Shibukawa M, Ohtani M, et al: Critical cerebral ischemia revealed by magnetic resonance imaging in a traumatic carotid-Cavernous fistula without high-risk - patterns on angiograms: a case report. J Trauma 2002;53:109-111.

10 Borba R, Sonda I, Dini LI, Calcagnotto FN, Marchett N, Cobalchini PC: Carotid-cavernous fistula with lethal epistaxis: case report. Arq Neuropsiquiatr 2001;59:276-279.

11 Yu JK, Hwang G, Sheen SH, Cho YJ: Bilateral visual loss as a sole manifestation complicating carotid cavernous fistula. J Korean Neurosurg Soc 2011;49:229-230.

$\checkmark 12$ Serbinenko FA: Balloon catheterization and occlusion of major cerebral vessels. J Neurosurg 1974;41:125145.

13 Debrun GM: Treatment of traumatic carotid-cavernous fistula using detachable balloon catheters. AJNR Am J Neuroradiol 1983;4:355-356.

14 Gomez F, Escobar W, Gomez AM, Gomez JF, Anaya CA: Treatment of carotid cavernous fistulas using covered stents: midterm results in seven patients. AJNR Am J Neuroradiol 2007;28:1762-1768. 
Case Reports in

Ophthalmology

Case Rep Ophthalmol 2015;6:482-487

\begin{tabular}{l|l}
\hline DOI: $10.1159 / 000443141$ & C 2015 The Author(s). Published by S. Karger AG, Basel
\end{tabular} www.karger.com/cop

Demartini Jr. et al.: Unilateral Direct Carotid Cavernous Fistula Causing Bilateral Ocular Manifestation
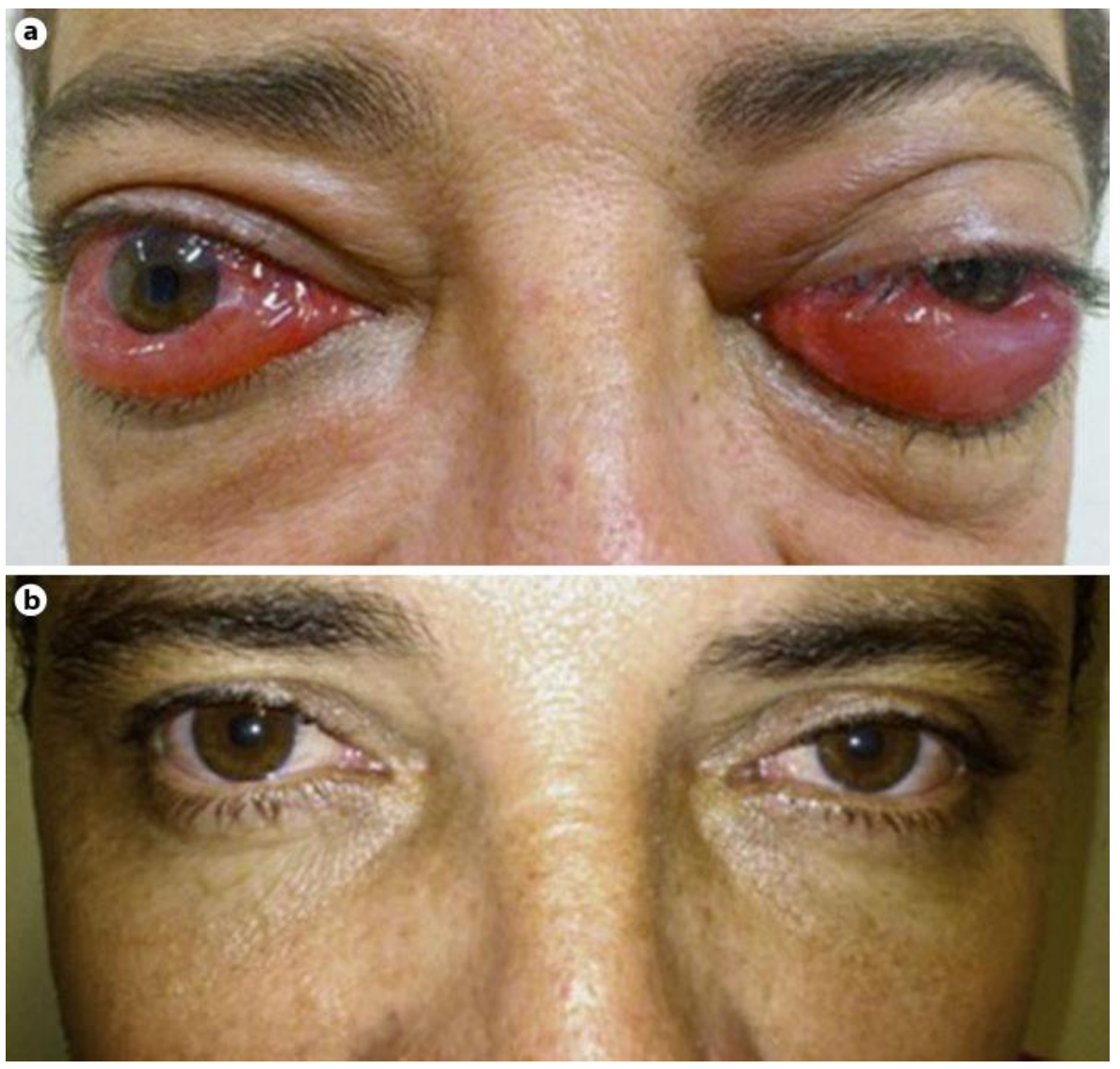

Fig. 1. a Bilateral proptosis, chemosis and conjunctival injection at admission. b Significant improvement at the 21 st postoperative day. 


\section{Case Reports in \\ Ophthalmology}

\begin{tabular}{l|l}
\hline Case Rep Ophthalmol 2015;6:482-487 \\
\hline DOI: 10.1159/000443141 & $\begin{array}{l}\text { ○ } 2015 \text { The Author(s). Published by S. Karger AG, Basel } \\
\text { www.karger.com/cop }\end{array}$ \\
\hline
\end{tabular}

Demartini Jr. et al.: Unilateral Direct Carotid Cavernous Fistula Causing Bilateral Ocular Manifestation
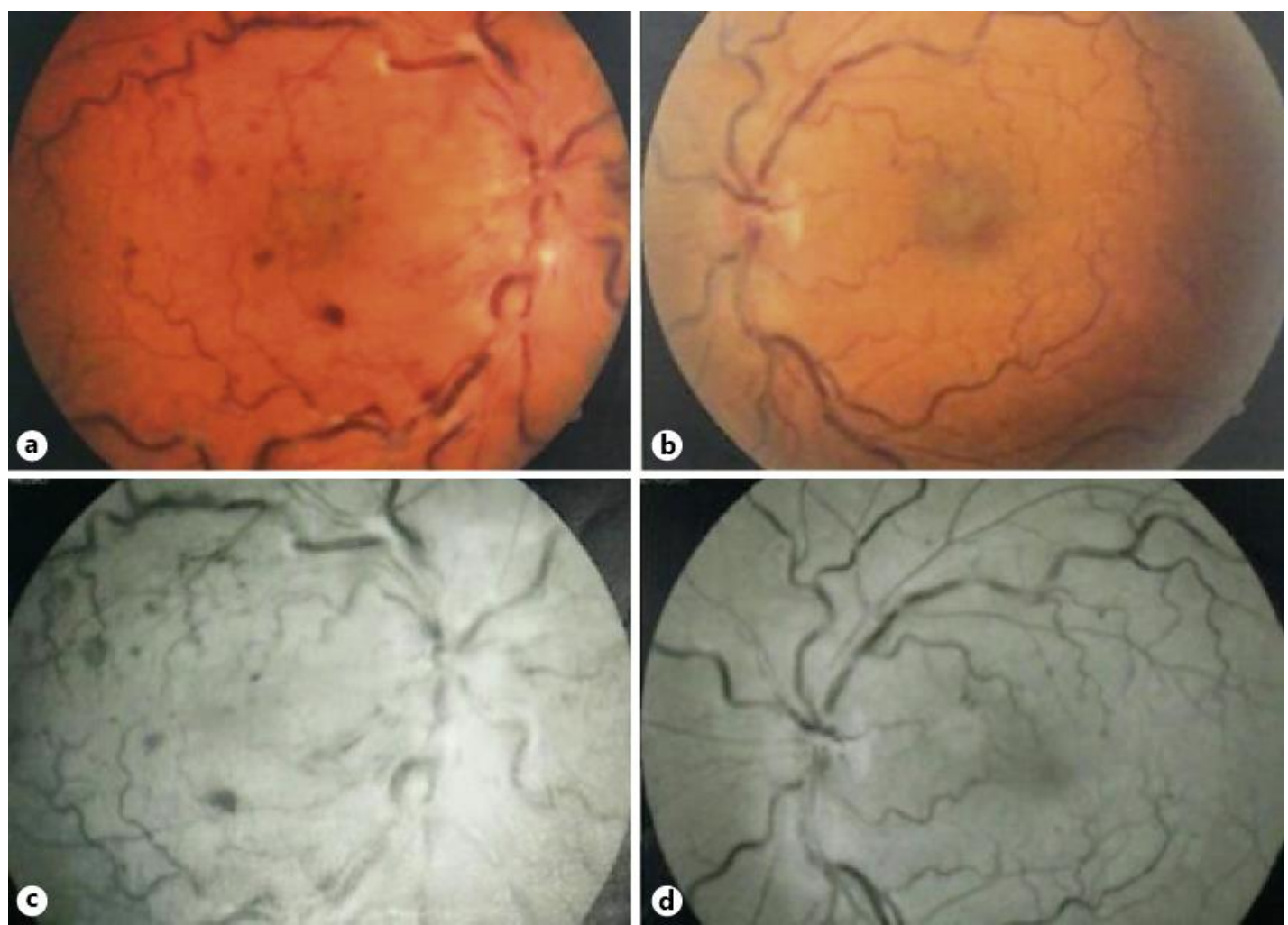

Fig. 2. a, b Fundus retinography showing bilateral papilledema and retinal hemorrhage. c, d FA showing bilateral venous dilation.
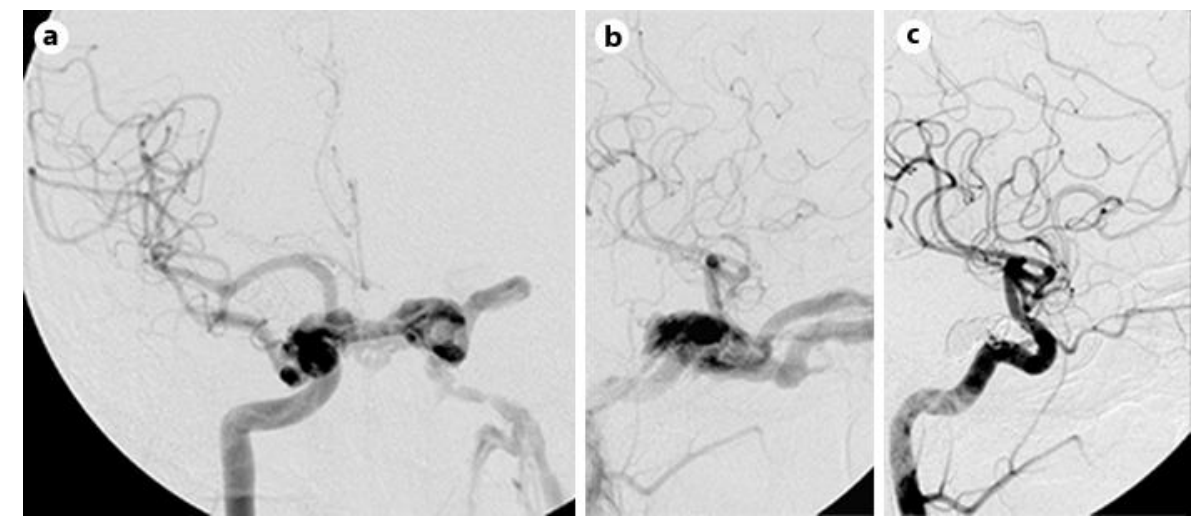

Fig. 3. a Right internal carotid angiogram (anteroposterior view) showing right carotid cavernous fistula filling contralateral cavernous sinus through the contralateral intercavernous sinus. b Anteroposterior view showing bilateral ectasia of superior ophthalmic veins, occluded with detachable balloon and coils (c). 